\title{
COLLABORATION AND COMMITMENT HOLD THE KEY FOR NEW DRUG DEVELOPMENT IN INDIA
}

\section{Dear Reader,}

Modern drug discovery is becoming day by day more challenging due to the stringent regulatory requirements coupled with a high rate of attrition, making drug discovery extremely cost intensive. This has brought academic institutions worldwide to the forefront to discover new drugs by finding new targets. Post-independence India had no indigenous Pharma capability and the then Government jump started the activity by setting up National laboratories such as CDRI, IICT, NCL, IIM and others under the auspices of CSIR for

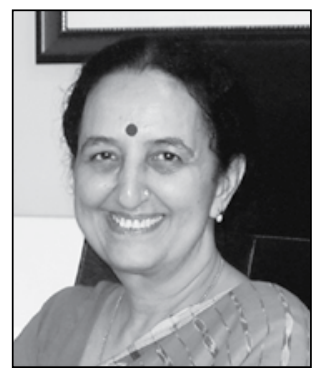
providing technologies to the emerging Pharma Industry that introduced very affordable quality drugs over the years enabling India to emerge as the "cradle of pharmacy" for the World. Having necessary expertise and competence in all aspects of drug discovery \& development, India should aspire to introduce new drugs towards the unmet needs of our population. India has a very high incidence of fatty liver disease, type 2 diabetes, cardiovascular disorders and depression. Newly introduced Phytopharmaceutical guidelines offer us a new opportunity for making Ayurvedic drugs to be prescribed by Clinicians for local use and subsequently for global use.

I would like to narrate the history of discovery and development of alpha-beta Arteether in India for the benefit of Readers. Joint development and licensing out of Arteether happened in 1997 by Central Drug Research Institute (CDRI) to Themis Pharmaceuticals. It marks a day when an indigenous inexpensive treatment for $P$. Falciparum malaria (cerebral malaria) became available to our vast population. The day also marked the culmination of sustained collaboration between two public funded institutes, CDRI \& CIMAP (Central Institute of Medicinal and Aromatic Plants) under the championship of Dr Nitya Anand (CDRI) and Dr Akthar Hussain (CIMAP). Most notable was the foresight of Dr Nitya Anand who procured Artemesia annua (a traditional herb having history of use in Chinese medicine for the treatment of fever, inflammation and malaria) seeds from China and its sustained cultivation by Dr Akhtar Hussain's team at CIMAP with a view to develop new anti-malarials. The fact that WHO was also pursuing artemether, did not deter the indigenous efforts and is demonstrative of their deep commitment. Developed at a cost of only about Rs. 23 crores (Amit Mishra, An Indian Drug Discovery Success Story - and Why It Might Not Happen Again, The Wire, 16 August 2017), Arteether has been exported (thousands of crores) to various countries and is now manufactured/ marketed by a plethora of Pharma companies leading to an extremely affordable drug against a potential lethal disease.

This brings another aspect of Drug development to our mind. What is the role of "Champions" in drug discovery and development? Why in present times are we short of champions likes of Dr TR Govindachari, Dr Nitya Anand, Dr Sukh Dev, Dr Yusuf Hamied, Dr Parvindar Singh, Dr K Anji Reddy and many such committed stalwarts who had shaped the present Pharma Industry? Is this factor alone the reason behind few new indigenous drug introductions in India? Answers to these questions lie possibly in the changed social, institutional, regulatory regime and financial burden. Our emphasis on individualistic excellence alone has prevented committed academic teams from collaborating towards a common goal over a sustained period, and dithering focus and public commitment to this vital area has also emerged as a major factor. On the brighter side, Dr Kiran Majmudar Shaw (Biocon) and Dr Pankaj Patel (Zydus Cadila) have emerged as serious committed champions of affordable drugs. 
The need of the hour is to forge Academia-Industry collaborations based on mutually complementary strengths with the Government acting as the catalyst. In the recent past, the success of such focused interventions like BIRAC, and NIMTLI etc has demonstrated the appropriateness of such an approach. Indian Pharma has grown in volume and its profitability has primarily been dependent on generics but the next phase of growth can only come from new drug introductions. The horizontal spread of biotechnological capabilities and research across the country presents an exploitable resource for biopharmaceutical discovery. The future of Indian Pharma securely lies in sustained new drug development ventures utilizing innovative strategic collaborations.

Dr Madhu Dikshit,

FNA, FNASc, FASc, FAMS, JC Bose National Fellow THSTI National Chair, NCR Biotech Science Cluster Former Director,CSIR Central Drug Research Institute, Lucknow Former Visiting Professor, Department of Bioscience \& Bioengineering, Indian Institute of Technology, Jodhpur-342037

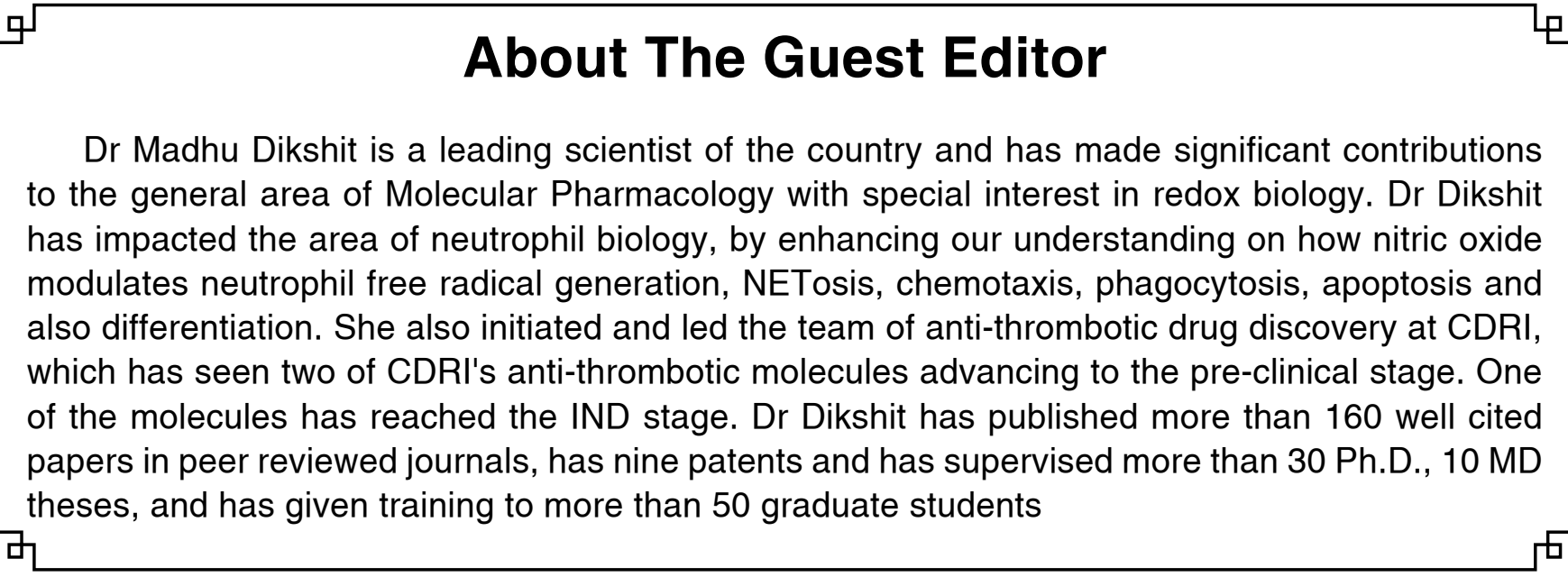

If you would like to comment on the Guest editorial please write to us at publications@idmaindia.com 